\title{
Microbial Fuel Cell for Renewable Energies Generation from Manure Treatment
}

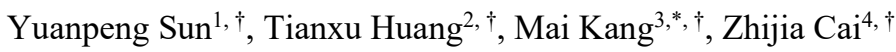 \\ ${ }^{1}$ Environmental Engineering, Lancaster University College at Beijing Jiaotong University, Weihai 264200, China \\ ${ }^{2}$ Chemical Engineering, Guangdong Israel Institute of Technology, Shantou 515063, China \\ 3,* School of Chemistry, South China Normal University, Guangzhou 511436, China \\ ${ }^{4}$ Engineering Department, Purdue University Northwest, Hammond 46323, US \\ $\dagger$ These authors contributed equally.
}

\begin{abstract}
In the process of society, high-density livestock farms have developed rapidly to satisfy the increasing demand for meat products. Excessive wastewater from the livestock farms accordingly brought multiple pollution and deteriorate the environment, with the wastewater containing abundant chemical energy regarded as futility. Furthermore, the ingredients of wastewater varied from distinct livestock farms as a result of different animal feeding habits. Consequently, it is a necessity for specific wastewater treatment applied to a certain farm to control various pollution incidents while effectively recovering the potential chemical energy in wastewater. Microbial fuel cell, a device that converts chemical energy in the organic matter directly into electrical energy by a microorganism, is expected to be integrated with the existing wastewater treatment systems to make up for the shortcomings of existing technologies, improve the treatment efficiency and energy recovery rate. Therefore, it is a predictable trend for the microbial fuel cell to be combined with the traditional farm wastewater treatment system. This article demonstrates two traditional manure treatment methods: composting and biogas fermentation, followed by an evaluation of four advanced wastewater treatment technologies merged with microbial fuel cell. It is concluded that incorporating microbial fuel cells with separate wastewater treatment system will be a consequential sustainable development strategy in the future, with the purpose of fecal water treatment and energy recovery efficiently achieved.
\end{abstract}

\section{Introduction}

Under the premise of global economic development, the global demand for edible meat has risen, and the rapid development of animal husbandry has also brought a large number of livestock and poultry manure that needs to be processed. A large number of feces will cause a large amount of pollution due to improper treatment, also cause a large amount of waste of organic and energy resources. Manure treatment thus has become an issue of concern in many farms in order to adequate their productions to the requirements of available arable lands.

Currently, manure management technology used in China mainly includes composting, separation of manure, biogas production and discharge of liquid manure to recipients such as public sewers or ponds. For instance, biogas technology is considered one of the solutions to environmental problems caused by manure management. Of benefits can be mentioned that biogas is renewable and clean and can be used for heating and cooking, which saves trees, thus reducing deforestation.

This article mainly discusses the influence of manure on environmental pollution, composting and biogas methods, as well as the application of different electrochemical microbial methods on manure treatment.

\section{The pollution characteristics of different types of manure}

\subsection{Types of pollution from livestock breeding}

\subsubsection{Water pollution}

Water pollutants produced by livestock and poultry farming are mainly organic matter, nitrogen, and phosphorus. These pollutants released into the water body will cause the rapid growth of algae and lead to a generation of a large number of aquatic organisms. The dead organisms would lead to excessive bacterial content

*Corresponding author e-mail: 20182431018@m.scnu.edu.cn 
of water bodies, polluting groundwater and reducing the concentration of dissolved oxygen in groundwater. Therefore, the water quality seriously decreased and pollution spread. Furthermore, the pollution components are too complex to decompose $[1,2]$.

\subsubsection{Soil pollution}

The large-scale breeding mode will lead to animal husbandry and poultry feces discharge far beyond soil tolerance, and unprocessed straight feces will lead to land plate knots and soil biological imbalance [2].

\subsubsection{Atmosphere pollution}

Atmospheric pollutants mainly include dust with germs and toxic and odorous gases composed of sulphides, ammonia and hydrogen sulfide. It is more likely to reduce life quality and spread disease [2].

\subsection{The pollution characteristics of different kinds of manure.}

This paper only makes a general estimate of animal breeding pollution, so the source of excreta is divided into livestock (e.g. pigs, cows and goats) and poultry. Table 1 shows the average contents of pollutants from the feces and urine.

\begin{tabular}{|c|c|c|c|c|c|}
\hline Category & COD & BOD & $\mathrm{NH}_{3}-\mathrm{N}$ & $\mathrm{TN}$ & $\mathrm{TP}$ \\
\hline ig manure & 52.00 & 37.30 & 3.08 & 5.88 & 3.41 \\
\hline Pig urine & 9.00 & 5.00 & 1.43 & 3.33 & 0.52 \\
\hline $\begin{array}{l}\text { Goat's } \\
\text { manure }\end{array}$ & 4.63 & 4.10 & 0.80 & 7.50 & 2.60 \\
\hline $\begin{array}{l}\text { Goat's } \\
\text { urine }\end{array}$ & 4.63 & 4.10 & 0.80 & 14.00 & 1.96 \\
\hline $\begin{array}{l}\text { Cows } \\
\text { manure }\end{array}$ & 31.00 & 24.53 & 1.71 & 4.37 & 0.40 \\
\hline $\begin{array}{l}\text { Cows urine } \\
\text { Poultry }\end{array}$ & 6.00 & 4.00 & 3.47 & 8.00 & 0.40 \\
\hline $\begin{array}{l}\text { Chicken } \\
\text { manure }\end{array}$ & 45.00 & 47.87 & 4.78 & 9.84 & 5.37 \\
\hline $\begin{array}{l}\text { Ducks, } \\
\text { goose dung }\end{array}$ & 46.00 & 30.00 & 0.80 & 11.00 & 6.20 \\
\hline
\end{tabular}

COD: Chemical Oxygen Demand

BOD: Biochemical Oxygen Demand

NH3-N: ammonia-nitrogen

TN: Total Nitrogen

TP; Total Phosphorus

\section{Two traditional methods for manure}

Both biogas and composting turn wasted organic material into something useful. Biogas makes methane, which is collected and burned to generate electricity. Composting makes organic fertilizer, which is used by gardeners, golf course managers and farmers to grow plants.

\subsection{Compost Fermentation}

Aerobic Composting fermentation is a process of stabilizing the organic matter in the manure under aerobic conditions and relying on the action of aerobic microorganism (mainly aerobic bacteria). By mixing the manure and auxiliary materials required by the carbonnitrogen ratio, the manure will be fermented to produce organic fertilizer [6].

\subsubsection{Advantages}

1) Less odor produce

2) Easy to store, transport and use

\subsubsection{Disadvantages}

1) It needs to input a lot of oxygen.

2) It needs to make sure the ratio of manure and auxiliary materials

3) The temperature

\subsubsection{Process}

Before aerobic composting, the manure and the auxiliary need to be calculated. The composting is processing during the temperature getting high. It can be defined as four processes.

1) In the first stage when the temperature is lower than $45^{\circ} \mathrm{C}$, microorganisms are active, and the soluble organic matter in the compost would be used for vigorous reproduction.

2) In the second stage when the temperature increases to around $45{ }^{\circ} \mathrm{C}$, microorganisms are suppressed or die, and thermophilic microorganism replaces mesophilic microorganisms.

3) In the third stage when the temperature is higher than $45^{\circ} \mathrm{C}$, only parts of organic matter and newly formed humus which is more difficult to decompose remain in this maturity stage. At this time, the microbial activity decreases, the heat generation decreases, and the temperature decreases.

4) In the fourth stage when the temperature decreases, odor volatilization during the composting process would reduce.

\subsection{Biogas Fermentation}

Biogas fermentation is one of the most common methods used for manure treatment. It is suitable for mixing solids and liquids. During biogas fermentation, different kinds of various will catabolism, and the bacteria, parasites, and eggs will be killed. In the end, the combustible mixed gas call biogas would be formed, such as methane $\left(\mathrm{CH}_{4}\right)$ and carbon dioxide $\left(\mathrm{CO}_{2}\right)$ [7].

\subsubsection{Advantages}

1) Creating Biogas

2) Protecting forest and grass resources, reducing soil erosion 
3) Saving money

\subsubsection{Disadvantage}

1) High cost in the early time

2) Hard to find a place to place a biogas digester

\subsubsection{Process}

The sewage from the breeding farm flows to the regulating tank through the drainage ditch. A grille is installed in front of the regulating tank to remove the larger debris in the sewage. The manure cleared out manually is transported to the regulating tank, mixed with the sewage, and then flowed into the metering tank. The metering tank is equipped with a pump to send the material liquid to the anaerobic digester regularly and quantitatively. In order to keep the temperature in the anaerobic digester at about $35^{\circ} \mathrm{C}$, there is a steam heating system in the metering tank, and the steam is introduced from the boiler room. The metering tank and anaerobic digester are equipped with temperature sensors to adjust the amount of steam entering the regulating tank. Other heating methods can also be used. The generated biogas is desulfurized, dehydrated, and purified, and then enters the gas storage tank to be used as energy for production or life. The biogas residue is discharged regularly according to the situation and can be dried and used as organic fertilizer. The biogas slurry enters the post-processing system and is used as liquid organic fertilizer for farmland.

\section{Applications of microbial fuel cells in manure treatment}

Microbial fuel cells (MFCs) refer to the reactor systems that focus on producing electricity using biodegradable materials, which aims to produce electricity by using the electrons derived from biochemical reactions catalyzed by bacteria.

In MFCs, the electrons released by bacteria from the substrate oxidation in the anode compartment (the negative terminal) are transferred to the cathode compartment (the positive terminal) through a conductive material. In the cathode, the electrons are combined with oxygen and the protons diffused through a proton exchange membrane. MFCs require sustained electron release in the anode and electron consumption in the cathode.17 The attainable metabolic energy gain for bacteria is directly related to the difference between the anode potential and the substrate redox potential. The optimal design for MFC is still under investigation, and different materials for the electrodes as well as more selective membranes for proton exchange are being currently developed to enhance their performance. It seems that small cells connected in series offer higher potentials than bigger reactor volumes. Nowadays, the main drawback for the full-scale application of MFC is the cost of materials and the low buffering capacity of domestic wastewater. However, the latter are still scarce, mostly empirical and under initial development stages.
Overview, MFC is the subject of increasing attention due to its advantages of effective removal of organic matter, moderately expensive operating requirements, low sludge production, and the ability to produce power. This study focuses on the application of MFC technologies in manure treatment.

\subsection{Application of microbial fuel cell in treating swine wastewater containing sulfonamide antibiotics}

Swine wastewater is one of the major antibiotics' sources in the environment, owing to large amounts of antibiotics used as drugs and feed additives in swine industries. Sulfonamides (SMs) constitute one of the oldest and widely employed antibiotics for swine farms considering their economic and relative efficacy in some common bacterial diseases. According to Cheng et al. (2018), the concentration of SMs in swine wastewater worldwide is up to $324.4 \mu \mathrm{g} / \mathrm{L}$. As the global population increases and the demand for pig products also increases, the consumption of SMs will continue to rise in the future[8]. However, the removal of sulfamethoxazole (SMX) from pig wastewater has received little attention in recent years. It also aimed to explore the effect of different concentrations of sulfonamide combinations on electricity generation and organic matter removal in a doublechamber MFC. The removal efficiency and degradation kinetics of sulfonamide combination in the MFC were also analyzed in their study [8].

\subsubsection{A double-chamber MFC design}

A double-chamber MFC was employed in this study, and the anode and cathode are cylindrical graphite felt and carbon fiber brush respectively. The two chambers are separated by a cation exchange membrane (CEM) and connected by copper wires through a $1000 \Omega$ resistor. The anode chamber was inoculated by anaerobic sludge collected from a pilot-scale anaerobic digester and fed with synthetic swine wastewater. In this study, the reactor was carried out in closed circuit mode and open circuit mode (OC) respectively. In order to investigate the removal efficiency in MFC, OC can be regarded as a traditional anaerobic reactor.

\subsubsection{Performance of the double-chamber MFC}

1) Stable voltage output was achieved before SMS was added to MFC. The mean value was $551.1 \mathrm{mV}$ with continuous operating cycles. The voltage is stable during operation, indicating that the microorganisms in the anode chamber have a strong tolerance to SMS.

2) The overall chemical oxygen demand (COD) removal rate of MFC remained stable $(95.28 \% \sim 98.66 \%)$ after the addition of 100 and $300 \mu \mathrm{g} / \mathrm{L}$ SMS, which indicated that MFC could effectively remove COD $(>95 \%)$, and the COD removal rate of OC decreased significantly to $58.72 \%$ and $18.82 \%$. The treatment of MFC is obviously better than that of a traditional anaerobic reactor. When other antibiotics were added to 
MFC, the degradation efficiency remained at a high level. This indicates that MFC has a strong resistance to antibiotic toxicity and has great potential in the treatment of wastewater containing antibiotics.

3) The research data showed that the simultaneous removal rates of SMX, SDZ and SMZ of MFC were higher than those of conventional anaerobic reactors at all initial concentrations. The researchers believe that the likely explanation is that the stimulation of electron transfer can promote microbial growth and microbial metabolism in the MFC anode.

In conclusion, the innovation point of this achievement is to focus on the combination of sulfonamide antibiotics. Results show that MFC can effectively remove a large number of organic matter in pig wastewater and the addition of SMS may increase electricity generation under certain conditions. More importantly, the simultaneous removal of SMX, SDZ and SMZ in the MFC was higher than those in the conventional anaerobic reactor.

\subsection{Application of a large - scale MFC system in the sustainable treatment of manure waste}

MFCs have always been considered a low-cost technology of wastewater treatment. This is a successful MFC system that has a larger scale than the others.

\subsubsection{A large - scale MFC system design and pilot operation}

This system is made up of $12 \mathrm{MFC}$ reactors with a volume of $110 \mathrm{~L}$, using a pump to control the outflow of swine wastewater. Each MFC reactor had a rectangular shape with internal dimensions and a volume of $7.9 \mathrm{~L}$. The anode was composed of twenty graphite fiber brushes. All carbon brushes were connected in series as one electrode. Two gas diffusion cathodes were placed on both sides of the reactor and connected in series. Flow guides were built into each reactor to direct the flow of the solution inside the reactors.
Twelve MFC reactors were connected in series with a consecutive flow of the solution from Reactor 1 to Reactor 12. The overall volume of the system was $110 \mathrm{~L}$. The waste stream was gravity - fed into the reactors through the utilization of an elevated feeder box, and a peristaltic pump was used to control the outflow rate. The raw manure comes from a small-scale pig farm, and the pig excrements were mixed with tap water and blended to grind the solid waste into smaller particulates.

The system was operated for over 200 days in continuous mode with a hydraulic residence time of 4 hours. In the first month, the system is under intermittent operation. The concentration of CAD remained unchanged in the first two weeks. After the first month, the model was changed from intermittent operation into constant operation [9].

\subsubsection{Advantages of the large - scale MFC system}

This system achieved the goal to reach a high COD removal within a short hydraulic residence time (HRT) in a pilot-scale MFC system. It moves one step closer to applying the MFC system for real pilot-scale wastewater treatment.

\subsubsection{Performance of the MFC system}

Electrochemical performance: The maximum current density was $102 \pm 8 \mathrm{~mA} / \mathrm{m}^{2}\left(1,013 \pm 73 \mathrm{~mA} / \mathrm{m}^{3}\right)$, which was achieved under the resistance of $47 \Omega$. Another MFC treatment can reach a current density of high- $228 \mathrm{~mW} / \mathrm{m}^{2}$ at $1,000 \Omega[10]$.

Chemical analysis of wastewater composition: During the first 110 days, the COD removal reached a peak at the beginning period of constant operation (Figure 1 ). The organic removal of the system is between 1-5 $\mathrm{kg} / \mathrm{m}^{3}$ per day, which is equivalent to parent aerobic treatment and small-scale MFCs system.

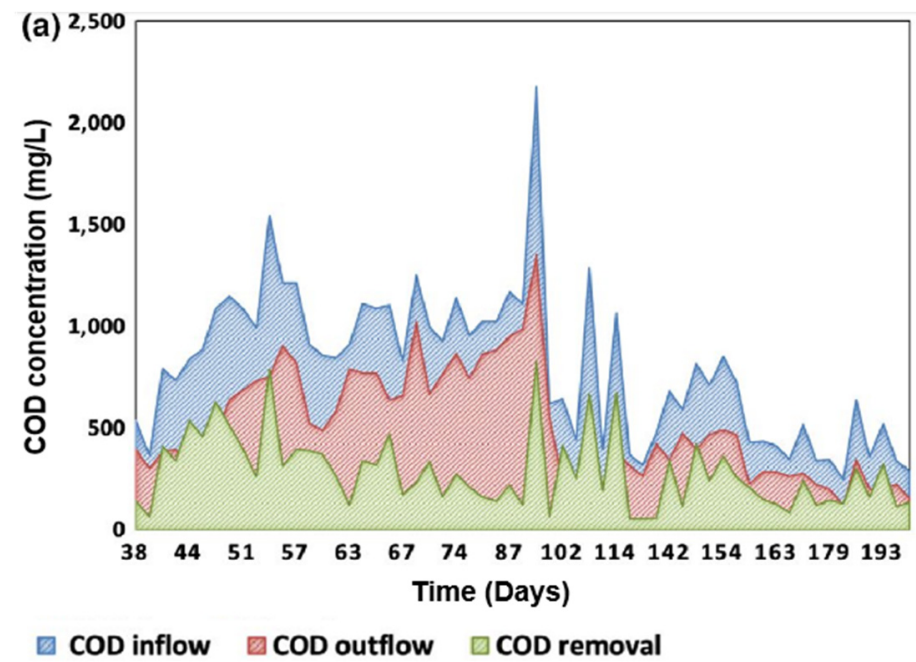




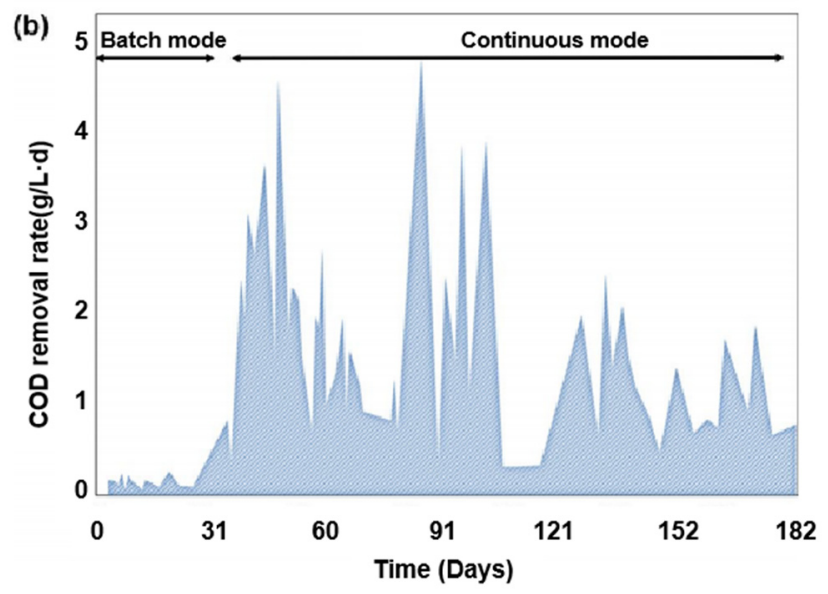

Figure 1 (a) COD concentration of the influent, effluent and the COD removal for the pilot, and (b) COD treatment rate over time.

On day 95 , the maximum COD removal was about 5.0 $\mathrm{kg} \mathrm{COD} / \mathrm{m}^{3}$ and COD loading was $2,200 \mathrm{mg} / \mathrm{L}$. The maximum COD removal rate was $65 \%$, which was recorded on day 102. The minimum COD removal rate was recorded at the enriching period. Zhuang et al. reported that the COD removal reached $83 \%$ under a COD loading of $1,000 \mathrm{mg} / \mathrm{L}$ and HRT of $60 \mathrm{hr}$ [10]. Kim et al. reported a COD removal of $59 \pm 6 \%$ with $16.7 \mathrm{hr}$ retention time. These studies observed obvious solid sedimentation, which was considered to be the reason for high COD removal [11]. In this method, solid sedimentation was not observed. But the COD removal still reached $65 \%$ 。

This study shows a large-scale MFCs system that can treat swine wastewater constantly in a small-scale pig farm with an HRT of $4 \mathrm{hr}$. This system has worked for 2 years and is still operating. The recorded maximum current density was $103 \pm 7 \mathrm{~mA} / \mathrm{m}^{2}\left(1,011 \pm 73 \mathrm{~mA} / \mathrm{m}^{3}\right)$. And the normalized energy recovery (NER) of this system at the resistance of $330 \Omega$ was $0.11 \mathrm{kWh} / \mathrm{kg}$ COD. This study is a breakthrough in the MFCs system. Before this, most MFCs systems are still remaining laboratory scale. Though some data seem great, those systems can't remain effective when treating farm-scale swine wastewater. In recent years, more and more studies focused on enlarging the scale of MFCs systems. It is proved that stacking MFCs together is an efficient way of scaling up. We believe better results will be achieved.

\subsection{Application of iron-air battery-MEC system in recovering the energy from swine wastewater}

The iron-air battery-MEC system is considered to deal with the excessive wastewater in the high-density livestock farms, among which swine wastewater is the typical nutritious pollution source. The iron-air batteryMEC system combines the microbial electrolysis cells (MECs) and iron-air battery into an integrated system, achieving the purpose of self-sufficiency and recovering the chemical energy in the swine wastewater. MEC, in this technology, is a device that uses microorganisms to convert chemical energy in swine wastewater directly into electrical energy. It can recover energy from organics in the form of hydrogen with each hydrogen ion obtaining electron. Electrogenic bacteria at the anode consume organic substances to produce electrons and hydrogen ions, and hydrogen gas is generated at the cathode when a small external voltage is applied.

$$
\begin{aligned}
& \text { Anode: Organic } \rightarrow \mathrm{CO}_{2}+\mathrm{H}^{+}+e^{-} \\
& \text {Cathode: } \mathrm{H}^{+}+2 e^{-} \rightarrow \mathrm{H}_{2}
\end{aligned}
$$

To solve energy consumption, This study combines metal-air batteries with a MEC system in treating domestic wastewater and groundwater. Metal-air batteries not only generate electricity but also produce coagulants at the anode. Focus on the other subsystem, metal-air batteries can serve as an alternative energy source, the coagulants generated in metal-air batteries and integrated with MECs can treat complex organic pollutants in wastewaters. Figure 2 illustrates the electron transfer and chemical reaction in the two subsystems. 


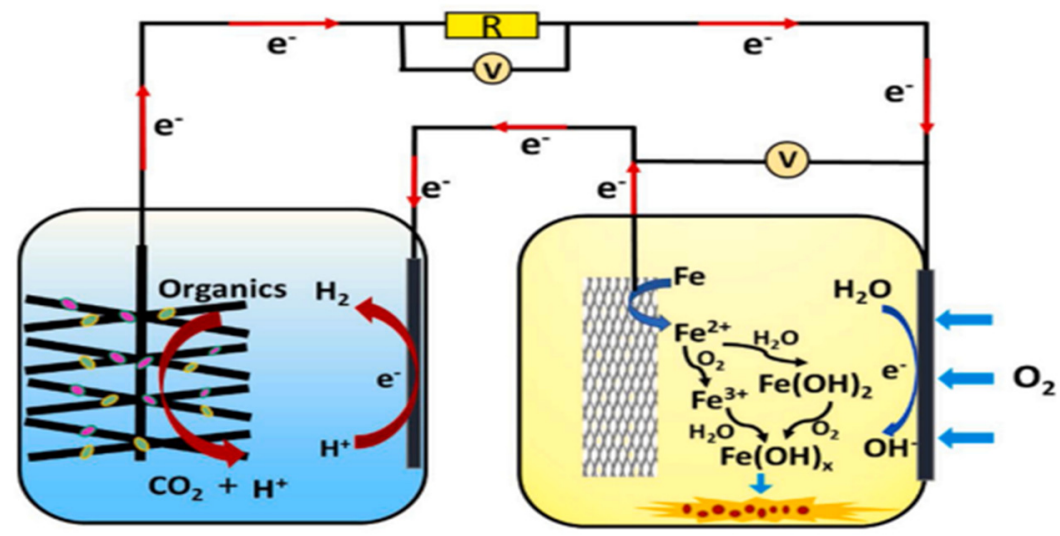

Figure 2 the electron transfer and chemical reaction in the two subsystems

\subsubsection{Advantages of the iron-air battery-MEC system}

The iron-air battery-MEC system absorbs oxygen from the external environment, converting the water into $\mathrm{OH}^{-}$ for the generation of $\mathrm{Fe}(\mathrm{OH})_{2}$ used for precipitating suspended solid, while hydrogen ions in the swine wastewater gain electrons which produce $\mathrm{H}_{2}$. More importantly, the production of $\mathrm{H}_{2}$ in the coagulant swine wastewater is far more efficient than the common one, which also means the complex organics could be removed effectively after coagulation.

With a series of experiment, the optimal removal rate of distinct components can be determined by changing different electrolyte solution concentrations. It can be obtained that the optimal concentration of the electrolyte is $35 \mathrm{~g} / \mathrm{L}$ comparing $\mathrm{NH}^{+}, \mathrm{COD}$, suspended solids and turbidity.

\subsubsection{Disadvantage of the iron-air battery-MEC system}

The iron-air battery-MEC system still confronts several challenges concerned with battery maintenance and efficiency. The first challenge is the electrode destruction in the internal iron-air battery due to the passivation of the iron electrode. In the pretreatment of swine wastewater, the active surface of the iron electrode in the iron-air system could be reduced which contributes to the lower capacity and thereupon influenced the utilization of swine wastewater with the production of $\mathrm{H} 2$ diminished. Secondly, the microbes existing in the microbial electrochemical systems (MES) could be vulnerable to impact by the chemical compounds in the swine wastewater, with the current limited by the hydrolysis and fermentation processes of organics at the anode [12,13]. Additionally, the electron transfer on the anode in MES could be remarkably influenced by the complex organic chemicals and ammonia with high concentration [14]. According to Xiaoyu, "the iron-air battery performance was likely impaired by its complexity and the specifics of the coagulation process in the battery" [15].

Additionally, the high concentration of COD in the swine wastewater could impede the performance of the battery, with a wealth of chemical energy not being recovered inside the swine wastewater. From Table 2, compared with swine wastewater (SW), the coagulant swine wastewater (CSW) containing less COD plays a greater role in $\mathrm{COD}$ removal and almost tenfold $\mathrm{H}_{2}$ production than SW.

Table 2 Comparison of the results of the present study and the other studies, wherein complex substrates were treated in MEC.

\begin{tabular}{|c|c|c|c|c|}
\hline \multicolumn{2}{|c|}{ Reactor } & \multicolumn{2}{|c|}{ Power Source } & $\begin{array}{l}\text { Wastewater } \\
\text { type }\end{array}$ \\
\hline \multicolumn{2}{|c|}{ Single chamber } & \multicolumn{2}{|c|}{$\mathrm{DC} 0.5 \mathrm{~V}$} & SW \\
\hline \multicolumn{2}{|c|}{ Single chamber } & \multicolumn{2}{|c|}{ iron-air battery } & SW \\
\hline \multicolumn{2}{|c|}{ Single chamber } & \multicolumn{2}{|c|}{ iron-air battery } & CSW \\
\hline $\begin{array}{l}\text { Operation } \\
\text { type(h) }\end{array}$ & conc & $\begin{array}{l}\text { D } \\
\text { tration } \\
\text { /L) }\end{array}$ & $\begin{array}{c}\text { COD } \\
\text { removal } \\
(\%)\end{array}$ & $\begin{array}{c}\mathrm{H}_{2} \\
\text { production } \\
\left(\mathrm{L} / \mathrm{m}^{3} \cdot \mathrm{d}\right)\end{array}$ \\
\hline 184 & & & $\begin{array}{l}12,000- \\
17,000\end{array}$ & 1000 \\
\hline 290 & & & $12500 \pm 700$ & 6 \\
\hline 113 & & & $8100 \pm 450$ & 57 \\
\hline
\end{tabular}

In conclusion, the iron-air battery-MEC system could be a promising technology for swine wastewater treatment to cut the expenditure on the additional energy input and environment protection.

\subsection{Continuous electricity generation integrated with fecal sewage treatment via ABR-MFC-MEC system}

The anaerobic baffled reactor-microbial fuel cellmicrobial electrolysis cell system (ABR-MFC-MEC) is beneficial for the interception of suspended particles and separation of hydrolysis-acidification and the methanogen processes with multi-stage baffles installed. Additionally, 
combining the microbial electrochemical facilities (MFCMEC) with the ABR unit could contribute to a weak current which can foster the nitrification-denitrification process in the system.

\subsubsection{Principle of ABR-MFC-MEC system}

Kuntke stated that the ammonium in the urine can be recovered through the utilization of the microbial fuel cell (MFC) technology while the electricity is generated continuously [16]. The microbes in the MFC system could oxidize the substrate, a surface on which the microorganisms grow and feed, and contribute electrons at the anode (Figure 3). These electrons will be transferred to the cathode on which the water is formed via the reaction of protons and oxygen [17]. Furthermore, in a MEC system, the partial micro-aerobic condition can be created by oxygen evolution in the region of the anode [18]. Hydrogen production in the cathode could stimulate the activation of methanogens and motivate the production of methane. In addition, the MEC unit assisted by MFC can significantly improve the denitrification efficiency, and the high short-circuit current of MFC is a necessary condition for the development of the coupling system. Using an anaerobic baffled reactor (ABR) process, the MFC can be powered in series to power the MEC reaction, while the MEC can convert various types of nitrogen sources to nitrogen [19]. The processes in the MFC and MEC electrodes can be expressed by the equations below:

$$
\text { Anode_MFC: } \mathrm{CH}_{3} \mathrm{COO}^{-}+4 \mathrm{H}_{2} \mathrm{O} \rightarrow 2 \mathrm{HCO}_{3}^{-}+9 \mathrm{H}^{+}+8 e^{-}
$$

Cathode_MFC: $2 \mathrm{NO}_{3}^{-}+10 e^{-}+12 \mathrm{H}^{+} \rightarrow \mathrm{N}_{2}+6 \mathrm{H}_{2} \mathrm{O}$

Anode_MEC: $2 \mathrm{NH}_{4}^{+}+2 \mathrm{H}_{2} \mathrm{O} \rightarrow 2 \mathrm{NO}_{2}^{-}+6 e^{-}+8 \mathrm{H}^{+}$

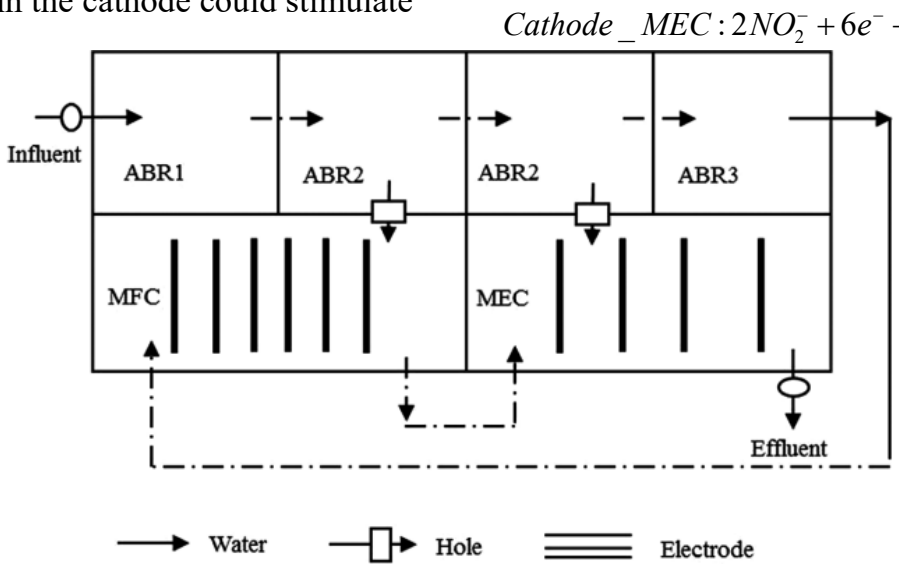

Figure 3 Schematic diagram of the single-chamber MEC

\subsubsection{Advantages of ABR-MFC-MEC system}

Multiple advantages can be achieved by the introduction of a microbial electrochemical device (MFC-MEC) into ABR. Firstly, electrochemical reactions promote the hydrolysis of solid organic matter. Secondly, coupling microbial electrochemical reaction improves the activity of methanogenic bacteria and inhibits the generation of hydrogen sulfide odor. Thirdly, the combination of MFC and MEC can also promote the process of nitrification and denitrification and improve effluent quality. Lastly, the output power of MFC is sufficient to support the operation of MEC, so as to achieve the balance of internal energy supply and demand.

\subsubsection{Performance of ABR-MFC-MEC system}

The significant indexes to evaluate the performance of the ABR-MFC-MEC system in treating fecal wastewater are the effluent COD and ammonia nitrogen. The mixture contains nitrate as cathode electrolyte, ammonium as anode electrolyte, in which ammonia nitrogen can be used as electron donor and reactant.

The main contents of biogas are $\mathrm{N}_{2}$ and $\mathrm{CH}_{4}$, which occupied nearly $45 \%$ of the total gas content. However, in a general anaerobic reactor, $\mathrm{CH}_{4}$ accounts for $55-65 \%$ and $\mathrm{CO}_{2}$ accounts for $30-45 \%$. Compared with the two, the gas composition of nitrogen is slightly lower than the content of $\mathrm{CH} 4$, which is mainly due to the micro-aeration that brings nitrogen into the system. Another reason is that the nitrogenous compounds are reduced to nitrogen. Its inhibition of methanogenic activity in the ABR unit can have a negative effect on $\mathrm{pH}[20]$.

The COD removal rate is sensitive to the change in hydraulic retention time. Generally, the longer the hydraulic retention time, the better the COD removal effect. In addition, the aeration rate also affects the ABRMFC-MEC combined power generation, the more bubbles on the electrode, the faster the reaction, and the output voltage is also increased. The results show that the COD concentration decreases with the increase of the input of the external electron acceptor.

Overview, this emerging process for the treatment of fecal wastewater introduces a coupled MFC-MEC unit into the $\mathrm{ABR}$ and processes and operates in an energy selfsufficient mode. In ABR, MFC is based on the redox configuration of the influent fecal wastewater, and the remaining electrical energy contributes to the formation of MEC and stimulates the microbial activity in the ABR unit, which greatly improves the ability of microorganisms to 
treat fecal wastewater and the recovery of electrical energy.

\section{Conclusion}

This article mainly discusses the benefits, drawbacks, and processes of composting and biogas methods, the most traditional and useful methods for manure treatment. Furthermore, MFC is the reactor system that focuses on producing electricity using biodegradable materials. It is the subject of increasing attention due to its advantages of effective removal of organic matter, moderately expensive operating requirements, low sludge production, and the ability to produce power.

MFC can effectively remove a large number of organic matter in pig wastewater and the addition of SMS may increase electricity generation under certain conditions. A large-scale MFCs system that can treat swine wastewater constantly in a small-scale pig farm was proposed, which is a breakthrough of the MFCs system.

The iron-air battery-MEC system combines metal-air battery and the microbial fuel cell, which is a new method that appears in the world today. It gives a new method to treat manure through a biology way. It significantly promotes the sedimentation of suspended particles in sewage and forms coagulants (metal hydroxides) for the adsorption of particles by consuming metal electrodes. Additionally, the system also has an excellent COD removal effect and efficient microbial power generation, which can be applied to farms that feed large livestock.

ABR-MFC-MEC system stimulates the activity of microbial communities and the efficiency of the nitrification-denitrification process by coupling the microbial electrochemical device (MFC-MEC) with the ABR unit and obtains electricity and gas by-product methane. The treatment effect of this system on ammonia nitrogen and COD is very significant, so it can be widely used in the sewage treatment system of poultry farms.

By comparing the traditional methods and MFC measures, the new methods will be more effective on the farm. Therefore, integrating microbial fuel cells with wastewater treatment systems will be a consequential sustainable development strategy in the future, and then the purpose of fecal water treatment and energy recovery efficiently will be achieved.

\section{References}

1. Liu Xiaoyong, Wang Xiu-bin, LI Shu-tian (2019). Phosphorus loading rates from livestock and poultry faeces, and environmental evaluation in China[J]. Journal of Agro-Environment Science, 38 ( 11 ): 2594-2608.

2. Liu, Y.F., Mayilai, A.N., Tang, S.Z., et al (2020). Pollution of Livestock and Poultry Feces and Counter Measures[J]. Grass-Feeding Livestock, 4:47-49

3. Tsai, W. T., \& Lin, C. I. (2009). Overview analysis of bioenergy from livestock manure management in Taiwan. Renewable and Sustainable Energy Reviews, 13(9), 2682-2688.
4. Loyon, L. (2017). Overview of manure treatment in France. Waste management, 61, 516-520.

5. Zhang, T., BU, M. D., \& Geng, W. (2012). Pollution status and biogas-producing potential of livestock and poultry excrements in China. Chinese Journal of Ecology, 31(5), 1241.

6. Senesi, N. (1989). Composted materials as organic fertilizers. Science of the Total Environment, 81, 521542.

7. Thu, C. T. T., Cuong, P. H., Van Chao, N., Trach, N. X., \& Sommer, S. G. (2012). Manure management practices on biogas and non-biogas pig farms in developing countries-using livestock farms in Vietnam as an example. Journal of Cleaner Production, 27, 64-71.

8. Cheng Dongle,Ngo Huu Hao,Guo Wenshan,Lee Duujong,Nghiem Duc Long,Zhang Jian,Liang Shuang,Varjani Sunita,Wang Jie. Performance of microbial fuel cell for treating swine wastewater containing sulfonamide antibiotics.[J]. Bioresource technology,2020,311.

9. Sofia Babanova, Jason Jones, Sujal Phadke, (2019). Continuous Flow, Large-Scale, Microbial Fuel Cell System for the Sustained Treatment of Swine Waste.

10. Kim, K. Y., Yang, W., Evans, P. J., \& Logan, B. E. (2016). Continuous treatment of high strength wastewaters using air-cathode microbial fuel cells. Bioresource Technology, 221, 96-101.

11. Zhuang, L., Yuan, Y., Wang, Y., \& Zhou, S. (2012). Long-term evaluation of a 10-liter serpentine-type microbial fuel cell stack treating brewery wastewater. Bioresource Technology, 123, 406-412.

12. S.B. Velasquez-Orta, E. Yu, K.P. Katuri, I.M. Head, T.P. Curtis, K. Scott, Evaluation of hydrolysis and fermentation rates in microbial fuel cells, Appl. Microbiol. Biotechnol. 90 (2011) 789-798.

13. N. Montpart, L. Rago, J.A. Baeza, A. Guisasola, Hydrogen production in single chamber microbial electrolysis cells with different complex substrates, Water Res. 68 (2015) 601-615.

14. M. Cerrillo, J. Oliveras, M. Vĩnas, A. Bonmatí, Comparative assessment of raw and digested pig slurry treatment in bioelectrochemical systems, Bioelectrochemistry 110 (2016) 69-78.

15. X. Han, Y. Qu, D. Li, Y. Dong, D. Chen, Y. Yu, N. Ren, Y. Feng, Combined microbial electrolysis celliron-air battery system for hydrogen production and swine wastewater treatment, Process Biochemistry 101 (2021) 104-110

16. Kuntke, P., Smiech, K. M., Bruning, H., Zeeman, G., Saakes, M., Sleutels, T. H., Hamelers, H. V., \& Buisman, C. J. (2012). Ammonium recovery and energy production from urine by a microbial fuel cell. Water Research, 46(8), 2627-2636.

17. Wang, X., Cai, Z., Zhou, Q., Zhang, Z., \& Chen, C. (2012). Bioelectrochemical stimulation of petroleum hydrocarbon degradation in saline soil using U-tube microbial fuel cells. Biotechnology and 
Bioengineering, 109(2), 426-433.

18. Wu, T., Zhu, G., Jha, A. K., Zou, R., Liu, L., Huang, X., \& Liu, C. (2013). Hydrogen production with effluent from an anaerobic baffled reactor (ABR) using a single-chamber microbial electrolysis cell (MEC). International Journal of Hydrogen Energy, 38(25), 11117-11123.

19. Cheng, S., \& Logan, B. E. (2011). High hydrogen production rate of microbial electrolysis cell (MEC) with reduced electrode spacing. Bioresour Technology, 102(3), 3571-3574.

20. Kim, I. S., Hwang, M. H., Jang, N. J., Hyun, S. H., \& Lee, S. T. (2004). Effect of low pH on the activity of hydrogen utilizing methanogen in bio-hydrogen process. International Journal of Hydrogen Energy, 29(11), 1133-1140. 